Research Article

\title{
Study of prescribing pattern of topical corticosteroids in dermatology out patients department in a tertiary care hospital in India
}

\author{
Rajan P. Nerurkar, Manish R. Kokane, Manthan Nikesh Mehta*
}

\begin{abstract}
Department of Pharmacology, Topiwala National Medical College and BYL Nair Hospital, Mumbai, Maharashtra, India

Received: 25 July 2016 Accepted: 28 August 2016

\section{*Correspondence to: Dr. Manthan Nikesh Mehta, Email: drmanthanmehta@ gmail.com}

Copyright: (C) the author(s), publisher and licensee Medip Academy. This is an openaccess article distributed under the terms of the Creative Commons Attribution NonCommercial License, which permits unrestricted noncommercial use, distribution, and reproduction in any medium, provided the original work is properly cited.

\begin{abstract}
Background: The selection of rational yet most effective treatment is an art to be learnt by most physicians. The advent of topical glucocorticoids has changed the way inflammatory dermatological conditions are managed. However, there is a constant need to keep a check on these prescriptions for their rationality. The present study was done to review the prescribing pattern of topical corticosteroids in dermatology outpatients at a tertiary care hospital.

Methods: This was a prospective observational study on 300 prescriptions of patients above 18 years of age receiving topical corticosteroids in the dermatological outpatient department of a tertiary care hospital in the time frame of June 2014 to August 2014. Data obtained was recorded in a structured case record form (CRF) and analysed for their prescribing pattern, adverse reactions and cost analysis within different socioeconomic classes. Data was analysed using relevant statistical tests. A P-value of less than 0.05 was considered significant.

Results: Data was collected from 300 patients with the mean age of $38.28 \pm 11$ years. The most common indication for prescription of topical steroids was eczema $(22.33 \%)$. The most commonly prescribed topical steroid was clobetasol $(68.66 \%)$ followed by mometasone $(11 \%)$, betamethasone $(9.33 \%)$ and halobetasol (3\%). Cream was the most frequently prescribed formulation $(85.66 \%)$. 28 patients $(9.33 \%)$ out of 300 showed adverse drug reactions, of which, erythema was the most common (50\%).

Conclusions: Topical corticosteroids are effective drugs in an array of dermatological diseases and abundant choices are available in different formulations. Optimal therapy involves careful consideration of factors such as potency, formulation, responsiveness and the cost of the topical steroid.
\end{abstract}

Keywords: Drug utilization, Skin conditions, Cost analysis, Prescriptions, Adverse events

\section{INTRODUCTION}

Prescribing drugs is an important skill which needs to be continuously assessed and refined. It reflects the physician's attitude towards selecting the most appropriate and rational treatment. Drug utilization study is a process by which quality of drug prescribing is measured with respect to some set criteria or standards. ${ }^{1}$

Dermatological conditions account for up to $2 \%$ of consultations in general practice worldwide. In India, the most prevalent dermatological conditions include dermatitis, urticaria, fungal skin infections, acne, alopecia, psoriasis, skin cancer and adverse drug reactions on the skin. ${ }^{2}$

Topical glucocorticoids have revolutionized dermatologic therapeutics and are cornerstone of therapy in inflammatory skin diseases. Their therapeutic range varies from mild self-limiting conditions to life threatening problems. They reduce symptoms of inflammation, but do not address the underlying cause of disease. $^{3}$ The ultimate goal of dermatological therapy is to use the safest and least number of drugs in order to 
obtain the best possible effect in the shortest period at a reasonable cost. One step to achieve this is to monitor, evaluate and therapeutically analyse the prescribing pattern of drugs.

As there is a paucity of studies in this area among dermatological outpatients, we tried to gather information regarding the prescribing pattern of topical corticosteroids for various skin diseases, the formulations used and their adverse effect profile at a tertiary care teaching hospital.

The present study was undertaken to review the prescribing pattern of topical corticosteroids in dermatology outpatient department, to analyse the possible adverse symptoms experienced by the patients, to analyse and compare the cost of various topical corticosteroids within different socioeconomic classes in a tertiary care hospital in Mumbai.

\section{METHODS}

This prospective observational study was conducted on patients who were receiving topical corticosteroids in the dermatology OPD of tertiary teaching hospital. Institutional ethics committee permission was obtained prior to the initiation of study. The data was collected after obtaining written informed consent from patients. A total of 300 prescriptions of patients above 18 years of age receiving topical corticosteroids in the dermatological outpatient department and willing to participate in the study were collected from June 2014 to August 2014. Paediatric patients and those unwilling to participate in the study were excluded.

\section{The study consisted of 3 parts}

Part I: analysis of prescribing pattern of topical corticosteroids

Data was obtained from the prescriptions and one-to-one interview of the patients and was recorded in a structured case record form (CRF). Data assessed from the prescriptions included the demographic profile (gender, age), indications, potency of the steroid, drugs prescribed by generic or brand name, number of drugs prescribed from hospital pharmacy or outside pharmacy, prescribed in combination with antibiotics, antifungal and those prescribed from WHO essential medicine list (EML) $2011 .^{4}$

\section{Part II: analysis of adverse drug reactions of topical} corticosteroids

Patient who were already taking topical corticosteroids were asked about any clinical adverse effects.

Part III: cost analysis of topical corticosteroids within different socioeconomic classes
If topical corticosteroids were prescribed from hospital schedule, then the actual cost was obtained from the medical store section of the hospital. If topical corticosteroids were prescribed from outside pharmacy then the maximum retail price of the brand preparation was obtained from current index of medical specialities (CIMS). The socioeconomic class of patients was determined by Kuppuswamy's socioeconomic scale. ${ }^{5}$

\section{Statistical analysis}

Descriptive statistical terms such as mean, median, standard deviation, percentage, etc. were used to describe the data as appropriate. Comparison of cost among various socioeconomic status were done using Kruskal Wallis test followed by Dunn's post hoc test for multiple comparisons. Correlation of socioeconomic class of the patient with the cost of the prescribed topical corticosteroids preparation was done using Spearman's rank correlation coefficient. $\mathrm{P}$ value less than $5 \%$ was considered significant. Microsoft Excel 2013 and Graph Pad Instat version 3 were used for statistical analysis.

\section{RESULTS}

Data was collected from 300 patients. The mean age of the study population was $38.28 \pm 11$ years. Highest number of patients were between the age group of 18-30 years $(30.66 \%)$ followed by $31-40$ years $(29 \%)$. Amongst 300 patients, 223 were males and 77 were females.

According to the Kuppuswamy's scale, $59 \%$ of patients belonged to the lower middle class, $25 \%$ belong to upper middle class and $10 \%$ were of upper lower class

Table 1: Disease pattern of patients receiving topical corticosteroids.

\begin{tabular}{|ll|}
\hline Diseases & Number of patients (\%) \\
\hline Eczema & $67(22.33 \%)$ \\
\hline Psoriasis & $42(14 \%)$ \\
\hline Vitiligo & $32(10.66 \%)$ \\
\hline Alopecia areata & $27(9 \%)$ \\
\hline Lichen planus & $26(8.66 \%)$ \\
\hline Allergic contact dermatitis & $23(7.66 \%)$ \\
\hline Polymorphous light eruption & $17(5.66 \%)$ \\
\hline Systemic lupus erythematosus & $13(4.33 \%)$ \\
\hline Fixed drug eruption & $12(4 \%)$ \\
\hline Pemphigus & $09(3 \%)$ \\
\hline BullousPemphigoid & $03(1 \%)$ \\
\hline Generalised pruritus & $08(2.66 \%)$ \\
\hline Dermatitis herpetiformis & $03(1 \%)$ \\
\hline Chronic cutaneous lupus & $02(0.66 \%)$ \\
\hline Oral submucous fibrosis & $13(4.33 \%)$ \\
\hline Urticaria & $03(1 \%)$ \\
\hline Airborne contact dermatitis & $02(0.66 \%)$ \\
\hline
\end{tabular}


The most common indication was eczema (22.33\%) followed by psoriasis (14\%) and vitiligo (10.66\%) for which topical corticosteroids were prescribed in the Dermatology OPD (Table 1).

Table 2: Potency of topical corticosteroids and its use.

\begin{tabular}{|llll|}
\hline $\begin{array}{l}\text { Topical } \\
\text { corticosteroid }\end{array}$ & Potency & $\begin{array}{l}\text { Prescribed } \\
\text { number }\end{array}$ & $\begin{array}{l}\text { Percentage } \\
\%\end{array}$ \\
\hline $\begin{array}{l}\text { Clobetasol } \\
(0.05 \%)\end{array}$ & Very potent & 206 & $68.66 \%$ \\
\hline $\begin{array}{l}\text { Halobetasol } \\
(0.05 \%)\end{array}$ & Very potent & 09 & $3 \%$ \\
\hline $\begin{array}{l}\text { Betamethasone } \\
\text { dipropionate } \\
(0.05 \%)\end{array}$ & Potent & 28 & $9.33 \%$ \\
\hline $\begin{array}{l}\text { Mometasone } \\
\text { furoate }(0.1 \%)\end{array}$ & $\begin{array}{l}\text { Moderately } \\
\text { Potent }\end{array}$ & 33 & $11 \%$ \\
\hline $\begin{array}{l}\text { Fluticasone } \\
(0.05 \%)\end{array}$ & $\begin{array}{l}\text { Moderately } \\
\text { Potent }\end{array}$ & 11 & $3.66 \%$ \\
\hline & $\begin{array}{l}\text { Moderately } \\
\text { Potent }\end{array}$ & 13 & $4.33 \%$ \\
\hline
\end{tabular}

Table 3: Adverse drug reactions (ADR) observed with topical corticosteroid.

\begin{tabular}{|c|c|c|}
\hline ADR observed & $\begin{array}{l}\text { Number } \\
\text { of patients }\end{array}$ & Drugs \\
\hline Erythema & $14(50 \%)$ & $\begin{array}{l}\text { Clobetasol - } 7 \\
\text { Betamethasone } \\
\text { dipropionate -1 } \\
\text { Halobetasol + } \\
\text { Fusidic acid - } 4 \\
\text { Mometasone + } \\
\text { Fusidic acid - } 2\end{array}$ \\
\hline $\begin{array}{l}\text { Cutaneous } \\
\text { atrophy }\end{array}$ & $9(32 \%)$ & $\begin{array}{l}\text { Clobetasol + } \\
\text { salicylic acid - } 3 \\
\text { Clobetasol - } 2 \\
\text { Halobetasol -1 } \\
\text { Halobetasol + } \\
\text { Fusidic acid - } 1 \\
\text { Mometasone - } 1 \\
\text { Mometasone + } \\
\text { Fusidic acid - } 1\end{array}$ \\
\hline Hypopigmentation & $3(10.71 \%)$ & $\begin{array}{l}\text { Clobetasol - } 2, \\
\text { Mometasone - } 1\end{array}$ \\
\hline Acne & $2(7.14 \%)$ & $\begin{array}{l}\text { Clobetasol - 1, } \\
\text { Betamethasone } \\
\text { dipropionate - } 1\end{array}$ \\
\hline Total & 28 & \\
\hline
\end{tabular}

The majority of topical corticosteroids prescribed were very potent steroids like clobetasol (68.66\%) and halobetasol (3\%) followed by moderately potent steroids like mometasone (11\%) and potent steroids like Betamethasone dipropionate $(9.33 \%)$. None of the mild potency steroids were prescribed during the study period. A detailed distribution is outlined in Table 2.
Cream was the most frequently prescribed (85.66\%) formulation, followed by ointment $(9 \%)$ and paste $(4.33 \%)$. The most commonly employed topical corticosteroid preparation as cream was clobetasol $(64.66 \%)$ followed by betamethasone dipropionate $(9.33 \%)$.

There were total 18 fixed dose combinations (FDCs) prescribed. i.e mometasone with fusidic acid and halobetasol with fusidic acid. ${ }^{5,13}$

Maximum topical corticosteroids were prescribed by generic name from hospital pharmacy (80.66\%) as compared to brand name from outside pharmacy $(19.33 \%)$. From the hospital pharmacy, clobetasol (64.66\%) was most commonly prescribed followed by betamethasone dipropionate $(9.33 \%)$. From outside pharmacy, mometasone $(4.33 \%)$ and triamcinolone $(4.33 \%)$ was most commonly prescribed.

In almost all the prescriptions, strength (98\%), frequency of application (97\%), site of application (99\%) and duration of treatment $(99 \%)$ were mentioned.

In our study, it was observed that none of the topical corticosteroids were prescribed from WHO EML 2011 namely hydrocortisone acetate and Betamethasone valerate.

\section{Table 4: Cost of different topical corticosteroids preparation.}

\begin{tabular}{|c|c|c|}
\hline $\begin{array}{l}\text { Topical } \\
\text { corticosteroids }\end{array}$ & $\begin{array}{l}\text { Hospital } \\
\text { pharmacy } \\
\text { cost ( rs.) }\end{array}$ & $\begin{array}{l}\text { Outside pharmacy } \\
\text { cost (rs.) }\end{array}$ \\
\hline Clobetasol & $\begin{array}{l}5.94(10 \\
\text { gm) cream }\end{array}$ & 32 (15 gm) cream \\
\hline $\begin{array}{l}\text { Clobetasol + } \\
\text { salicylic acid }\end{array}$ & & $\begin{array}{l}90(20 \mathrm{gm}) \\
\text { ointment }\end{array}$ \\
\hline Halobetasol & & $\begin{array}{l}106(15 \mathrm{gm}) \\
\text { ointment } \\
153(30 \mathrm{ml}) \text { lotion }\end{array}$ \\
\hline $\begin{array}{l}\text { Halobetasol + } \\
\text { Fusidic acid }\end{array}$ & & $95(10 \mathrm{gm})$ cream \\
\hline $\begin{array}{l}\text { Betamethasone } \\
\text { dipropionate }\end{array}$ & $\begin{array}{l}6.12(10 \mathrm{gm}) \\
\text { cream }\end{array}$ & $\begin{array}{l}17.50(10 \mathrm{gm}) \\
\text { cream }\end{array}$ \\
\hline $\begin{array}{l}\text { Betamethasone } \\
\text { dipropionate }+ \\
\text { clotrimazole }\end{array}$ & $\begin{array}{l}12(10 \mathrm{gm}) \\
\text { cream }\end{array}$ & $56(10 \mathrm{gm}) \mathrm{cream}$ \\
\hline $\begin{array}{l}\text { Mometasonefur } \\
\text { oate }\end{array}$ & $\begin{array}{l}51(10 \mathrm{gm}) \\
\text { cream }\end{array}$ & $80(10 \mathrm{gm})$ cream \\
\hline $\begin{array}{l}\text { Mometasone + } \\
\text { Fusidic acid }\end{array}$ & & $\begin{array}{l}132(5 \mathrm{gm}) \\
\text { ointment }\end{array}$ \\
\hline Fluticasone & & $\begin{array}{l}30(10 \mathrm{gm}) \text { cream, } \\
90(10 \mathrm{gm}) \\
\text { ointment }\end{array}$ \\
\hline Triamcinolone & & $33.42(5 \mathrm{gm})$ paste \\
\hline
\end{tabular}


The present study showed that 300 prescriptions contained 575 drugs with the average number of drug per prescription as $1.92 \pm 1($ Mean \pm SD) and median of 2 per prescription in our study.

Twenty eight $(9.33 \%)$ patients out of 300 showed adverse drug reactions to topical corticosteroids. Out of which, erythema $(50 \%)$ was the most common adverse drug reaction followed by cutaneous atrophy $(32 \%)$. Erythema, cutaneous atrophy, hypopigmentation, acne were mostly seen in patients receiving clobetasol. A drug-wise distribution is shown in Table 3.

The cost of various topical corticosteroids is outlined in Table 4. The distribution of cost of topical corticosteroids did not pass test for normality hence the median cost of therapy was compared between five socioeconomic classes using Kruskal Wallis test followed by Dunn's post hoc test for multiple comparisons.

The P-value was 0.8790 , considered not significant and median cost of topical corticosteroids was same in all socioeconomic classes.

\section{DISCUSSION}

In our study, out of 300 patients, $74.33 \%(\mathrm{n}=223)$ were males and $25.66 \%(\mathrm{n}=77)$ were females.

Now regarding age distribution, majority of patients (30.66\%) were in the age group of 18 - 30 years followed by $31-40$ years $(29 \%)$, which is comparable to $30.24 \%$ in the study done by Kumar AM et al. ${ }^{6}$ From the demographic data obtained, majority of the patients were from lower middle socioeconomic class (59\%) followed by upper middle class $(25 \%)$. This is in accordance with a study done by Narwane SP et al in which $51 \%$ and $33.66 \%$ patients were from lower middle socioeconomic class and upper middle class respectively. ${ }^{7}$

Diseases like eczema (22.33\%) topped the table, followed by psoriasis $(14 \%)$. The disease pattern is comparable to the study by Divyashanthi CM et al where diseases like eczema, psoriasis were the most common cause. ${ }^{8}$

As regards to the prescribing frequency of different topical corticosteroids, Topical corticosteroids, Clobetasol (very potent corticosteroids) was the most commonly prescribed in our study as this preparation is available in hospital pharmacy. This finding is similar to that of Narwane SP et al. ${ }^{8}$ None of the mild potency corticosteroids were prescribed during the study period. Similarly in a study carried out in the United States from 1989 to 1991 , it was found that dermatologists were 3.9 times more likely to prescribe very potent corticosteroids than were other physicians. ${ }^{9}$

The prescription of very potent corticosteroids should be limited when possible. Long and excessive use may carry the risk of suppression of the hypothalamic-pituitary-adrenal axis as well as local adverse effects. ${ }^{10}$

In our study, cream was the most frequently prescribed $(85.66 \%)$ formulation, followed by ointment $(9 \%)$.

In the present study, $80.66 \%$ drugs were prescribed by their generic name and the remaining $19.33 \%$ were in brand names. Majority (88\%) of topical corticosteroids were prescribed as single drug and $12 \%$ as combinations. This is in contrast to study conducted by Kshirsagar et al, in which generic drugs were prescribed in the range of $3 \%$ to $20 \%$. $^{11}$

In our study, topical corticosteroids were prescribed in combination with other topical agents like fusidic acid, salicylic acid, clotrimazole.

Among the drugs listed in the WHO's list of essential drugs for skin conditions the following topical corticosteroids were not available in hospital pharmacy$1 \%$ hydrocortisone, $0.1 \%$ betamethasone valerate. ${ }^{4}$ Low potency corticosteroids such as $1 \%$ hydrocortisone should be made available in hospital pharmacy as they cause lesser adverse drug reactions and not all skin condition requires high potency corticosteroids.

The practice of writing inadequate prescription information about topical corticosteroids may mislead the patient about usage of medications which may be responsible for overutilization or underutilization of corticosteroids resulting in potential side effects or subtherapeutic response to a drug, respectively. ${ }^{12}$ Under or over usage of these drugs can occur leading to serious consequences. Inadequate prescribing information and some irrational combinations can cause deleterious effects. In our study, in almost all the prescriptions, strength (98\%), frequency of application (97\%), site of application (99\%) and duration of treatment (99\%) were mentioned. ${ }^{19}$ Another study conducted on the prescription of topical corticosteroids in north Palestine showed that the quantity of the corticosteroid to be applied was not mentioned in $87.7 \%$ of the prescriptions and duration of use not mentioned in $71.6 \% .^{13}$

In our study, there were a total of 28 ADRs observed. Out of which, erythema $(50 \%)$ was the most common adverse drug reaction followed by cutaneous atrophy (32\%). erythema, cutaneous atrophy, hypopigmentation, acne were mostly seen in patients receiving clobetasol. So, careful consideration of patient's age, site of application, potency and efficacy of prescribed topical corticosteroid is required.

In a developing country like India, patient compliance is primarily dependent on the cost of treatment. ${ }^{14}$ The different costs (hospital pharmacy cost, outside pharmacy cost) were correlated by Spearman's Rho test. The cost of topical corticosteroids was not related with the socioeconomic score of the patient (Spearman's Rho = 
0.02969, P-value $=0.8790)$. Thus, the prescribing decision in our study was not influenced by the financial status of the patient.

There were few limitations in this study. This was a cross sectional study and patients were not followed up to evaluate the efficacy and safety of topical corticosteroids. This can be evaluated in future studies. In this study we did not measure the direct cost of treatment and the indirect costs. Further studies can be undertaken in these areas.

\section{CONCLUSION}

Low potency corticosteroids were not prescribed in the study and these can be added in hospital formulary this will avoid unnecessary use of very potent corticosteroids. Such modifications will decrease the adverse effects, increase the therapeutics benefit and improve the prescribing pattern.

Topical corticosteroids are the most commonly prescribed groups of drugs in dermatology. They are used for indications such as psoriasis, eczema, vitiligo, lichen planus, etc. They are effective for conditions that are characterized by hyperproliferation, inflammation and immunologic involvement. There are over 20 agents to choose from, and an abundance of formulations. Optimal therapy involves careful consideration of the disease's steroid responsiveness, as well as the potency, formulation, application frequency, and cost of the topical steroid. The study of prescription pattern is in fact, a part of medical audit involving compilation and monitoring of various prescriptions of medical practitioners.

\section{Funding: No funding sources}

Conflict of interest: None declared

Ethical approval: The study was approved by the Institutional Ethics Committee

\section{REFERENCES}

1. World Health Organization. Introduction to drug utilization research (online). Oslo, Norway: World Health Organization; 2003. Available at http://apps.who.int/medicinedocs/pdf/s4876e/s4876e. pdf. Accessed on 30 February 2016.

2. Ritter JM, Lewis LD, Timothy GKM, Ferro A. Drugs and the skin. A textbook of clinical pharmacology and therapeutics, $5^{\text {th }}$ edition, London, Hodder Arnold; 2008:411-419.

3. Werth VP. Systemic corticosteroids. In: Wolff K, Goldsmith LA, Katz SI, Gilchrest DA, Paller AS,
Leffel DJ (Eds.). Fitzpatrick's Dermatology in General Medicine. $7^{\text {th }}$ edn. Newyork, MC Graw Hill; 2008:2147.

4. World Health Organization. WHO Model list of Essential Medicines. $17^{\text {th }}$ edition, 2011. Available at http://www.whoindia.org/Linkfiles/_ Essential_ Medicines_List_EML17.pdf. Accessed on $2 \overline{3}$ February 2016.

5. Kumar BP, Dudala RS, Rao AR. Kuppuswamy's socioeconomic status scale- a revision of economic parameter for 2012. International journal of research and development of health. 2013;1:2-4.

6. Kumar AM, Noushad PP, Shailaja K, Jayasutha J, Ramasamy C. A study on drug prescribing pattern and use of corticosteroids in dermatological conditions at a tertiary care teaching hospital. International Journal of Pharmaceutical Sciences Review and Research. 2011;9:132-5.

7. Narwane SP, Patel TC, Shetty YC, Chikhalkar SB. Drug utilization and cost analysis for common skin diseases in dermatology OPD of an Indian Tertiary Care Hospital-A Prescription Survey. British Journal of Pharmaceutical Research. 2011;1:9-18.

8. Divyashanthi CM, Manivannan E. Prescribing analysis of corticosteroids among the dermatology inpatients in a tertiary care teaching hospital, Karaikal, Puducherry. Int J Pharm Bio Sci. 2014;5:324-30.

9. Stern RS. The pattern of topical corticosteroid prescribing in the United States, 1989-1991. J Am Acad Dermatol. 2006;35:183-6.

10. Walsh P, Aeling JL, Huff L, Weston WL. Hypothalamus pituitary- adrenal axis suppression by superpotent topical steroids. J Am Acad Dermatol. 1993;29:501-3.

11. Kshirsagar MJ, Langade D, Patil S, Patki PS. Prescribing patterns among medical practitioners in Pune, India. Bull. World Health Organization. 1998;76:271-5.

12. Rathod SS, Motghare VM, Deshmukh VS, Deshpande RP, Bhamare CG, Patil JR. Prescribing practices of topical corticosteroids in the outpatient dermatology department of a rural tertiary care teaching hospital. Indian J Dermatol. 2013;58:342-5.

13. Sweileh WM. Audit of prescribing practices of topical corticosteroids in outpatients dermatology clinics in North Palestine. Eastern Mediterranean Health Journal. 2006;12:161-69.

14. Gupta N, Sharma D, Garg SK, Bhargava VK. Auditing of prescriptions to study utilization of antimicrobials in a tertiary hospital. Ind J Pharmacol. 1997;29:411-5.

Cite this article as: Nerurkar RP, Kokane MR, Mehta MN. Study of prescribing pattern of topical corticosteroids in dermatology out patients department in a tertiary care hospital in India. Int $\mathrm{J}$ Basic Clin Pharmacol 2016;5:2194-8. 